furnished. He did not wish to be sounded ur to submit to any operative treatment whatever. I mention this particularly, as mechanical treatment could not have had anything to do with what subsequently followed. He wished me to prescrthe for him something which might possibly arrest the further formation of stone, and this I accordingly attempted. I heard nothing further about him, after a lapse of two years and a-hall, until a few weeks ago, when his doctor gou to-day. It would an about two mont to the " although they have urethra there has only once heen any haemorrhage, and that very urethr," tho from mainly of uric acid with a exight The whole mass is made up of sixty-four separate pieces as shown in the figure. (Fig. 2).

In closing these remarks, which, thongh arising out of geographical considerations relative to the subject matter, have been somewhat discursive, I f sel that as in other cases of preventable disorders that of stone, particularly when it occurs in endemic proportions, is deserving of further notice. It is a symptom and not a disease.

I have read with satisfaction in an issue of the Indian Medical Gazette, specially devoted to the subject of Stone (August, 1900), that my friend Dr. Keegan, whose work in India has so largely contributed to our knowledge, suggests that the Government of India, in places where stone in the bladder is so cornmon, should supply the most modern instruments necessary for its treatmont, and thus save a large number of lives. I would go a step further, and see if measures could not be taken to prevent concretion occurring. I cannot help thinking that more might be done in this direction, and that this aspect of the question is worthy of the consideration of so important a gathering.

REFERENCES.

等 Urinary Caleuli, 1873.4 Tise Influon"e of Colloids upon Crystalline Form and rohesion, London, 1879. 5 Lancet, 18,8, 6 Lancet, February gth, Igor. 7 Berl. klin. Woch., November 3 rd. 1879.

\section{A DEMONSTRATION OF}

\section{THE OPERATION OF INTERNAL URETHROTOMY AND OF A URETHROTOME.*}

Br C. B. LOCKWOOD, F.R.C.S., Assistant Surgeon to St. Bartholomew's Hospital.

GENTLEMEN.-The patient whois being anaesthetised is believed to have a urethral stricture or strictures, for strictures of the urethra are usually multiple. I speak tentatively because no urethral examination has heen made. The less the urethra is touched before the operation the better the after-progress of the case. Unless the exploratory proceedings are carried out under aseptic conditions the depths of the urethra, and perchance the bladder. are likely to be infected. Try to imagine the dangers of sepsis, or of septic urine, in contact with an incised wound in the depths of the male urethra. Surely the dangers of infection must be exceedingly great. Besides, the clinical history is a very clear one. Four years ago the patient, a man, aged 32, had an attack of gonorrhoea, and that was followed by difficult mirturition. The urine was expelled with much straining, and in a small stream, and at last an attack of retention had to be relieved with catheters. The day after his admission into the hospital the house. surgeon introduced a $5 \mathrm{~mm}$. $\rangle$ catheter into the bladder and left it in position during the night. I suppose he hoped to dilate the stricture which he had diagnosed at the membranous urethra. I have, however, no faith whatever in dilatation as a measure of permanent relief, and, moreover, it is attended with great dang $r$ of the introduction of sepsig. Fortunately, in this instance this danger has been averted. The urine ought to undergo a quantitative and qualitative examination before nearly all operations upon the genitourinary tract. This has been done, and we know that the quantity of acid urine passed in twenty-four hours is from 50 to $60 \mathrm{oz}$, that its specific gravity is 1020, and that its percentage of urea is 24 . It gives a haze of albumen on boiling, but this is unaccompanied by either pus or blood.

Of course we cannot be certain that the urine is aseptic, but we are sure that it is so near asepsis that it is not likely to complicate the operation. I know hardly anything more dangerous in urethral operations than septic urine. Now,

* Given in the operation theatre of the hospital.

$\dagger$ That is, $5 \mathrm{~mm}$. in circumference. The English scale is purely arbitrary, and very inexact and inconvenient. observe how the patient was prepared for the operation. Last night the usual aperient was given, and to-day no nourishment whatever has been taken for at least four hours before the time fixed for the operation. After a warm bath the pubes and scrotum were thoroughly shaved. It is singular to observe how often this precaution is omitted in this class of operation, but nevertheless nothing conduces more to sepsis than hair within the field of operation. The field of operation is prepared exactly as it would be for any other aseptic operation. Sterilized towels are placed over the thighs, flanks, and upper part of the abdomen. Then the penis and scrotum and the whole of the cutaneous surface of the abdomen within the ring of towels is disinfected with my solution of biniodide of mercury in methylated spirit (I part in 500). My hands and my assistants' hands are disinfected with the same solution, which takes not less than three minutes to soak in. The time is measured by the clock, another precaution which is so often omitted.

For the operation certain special instruments have to be provided. First a gauge for measuring the circumference of the bougies is essential. The numbers put upon catheters and bougies by the instrument makers are apt to be wrong. The gauge which $I$ hold up is an oblong metal plate made by Messrs. Arnold and Sons. One edge has upon it a scale graduated in centimetres and millimetres; the other edge a scale in inches and eighths of an inch. One set of apertures in the plate measure the circumference of the instruments in millimetres, and the other set by the English scale, which latter is, I believe, purely arbitrary. Next, a set of flexible bullet-ended bougies is required to locate and measure the stricture and to ascertain its characters. These are made of some form of rubber. Metallic instruments would be preferable because of the ease with which they can be sterilized. but I know of none which are flexible; those which are rigid are painful when passed through the membranous urethra. Those which I am about to use have been thoroughly scrubbed with soap and hot water, and soaked in biniodide of mercury lotion, I part in 2,000. Beginning with a large size, I find that No. $27 \mathrm{~mm}$. passes the external urinary meatus and stops abruptly at $12 \mathrm{~cm}$. therefrom (about $4 \frac{3}{4}$ in.). No. 27 ought to pass backwards until it reaches the compressor urethrae. Take care not to mistake that muscle for an organic stricture. I now proceed to pass smaller sizes, and find that No. $7 \mathrm{~mm}$ bullet-ended bougie passes the stricture at $12 \mathrm{~cm}$. and enters the bladder. As the bullet is withdrawn, it is caught at $12 \mathrm{~cm}$. from the meatus by the stricture, which imparts a feeling as if a piece of thread had been tied round the urethra. 'The inference is that I have to deal with an annular stricture $7 \mathrm{~mm}$. in circumference at $12 \mathrm{~cm}$. from the meatus, and just anterior to the triangular ligament.

Such a stricture as this, associated with aseptic urine, is most favourable for internal urethrotomy. But hitherto I have not been able to obtain a urethrotome which fulfils two indispensable conditions: (1) that it should be small enough to pass strictures of such narrow calibre ; and (2) that it should cut accurately from behind forwards. Teevan's urethrotome can be passed through a very narrow stricture, and, owing to its guide and the exit of urine along its grooved staff, its proper entry is assured, but it cuts from without inwards. In using Teevan's urethrotome I have always felt most uncomfortable whilst pushing the knife onwards through the stricture. On one occasion the staff was badly bent when withdrawn; and in others the knife shield during withdrawal caught in the cut, and had to be forcibly dislodged. Thompson's urethrotome is an excellent instrument, which cuts from behind forwards, but the smallest one will not pass through a stricture of less than II $\mathrm{mm}$. in circumference, and this stricture is $7 \mathrm{~mm}$. To meet these difficulties, Messrs. Arnold and Son have made for me a urethrotome which combines all the advantages of Teevan's and all the advantages of Thompson's. It consists of a staff with a groove in it, and of a tlexible guide to screw on the end of the staff (Fig. 1 ).

The flexible guide is made of metal, and, like the rest of the instrument, can be sterilized by heat. The groove in the staff serves a double purpose. As soon as it reaches the bladder urine runs along it, so that no doubt exists as to the position of the staff; next the groove carries a small knife (Fig. 2), which is pushed along it after the urine has been seen. A little catch causes the knife to project, when the handle is set free and withdrawn.

When the knife is hidden in the slot at the end of the groove the urethrotome and its guide taper gradually from $4 \mathrm{~mm}$ : in circumference to is mm. The two together are a wellbalanced and workmanlike instrument. 
Now, observe how this instrument behaves in action. My attempt to pass the staff without its flexible guide has failed. So now the guide is attached, and easily passes onwards into the bladder, followed by the staff. Now some urine escapes along the groove in the staff, so that the staff is through the stricture and in the bladder. Next, the knife is pushed along the groove and opened just beyond the strictore. The scale on the staff enables me to do this quite accurately.

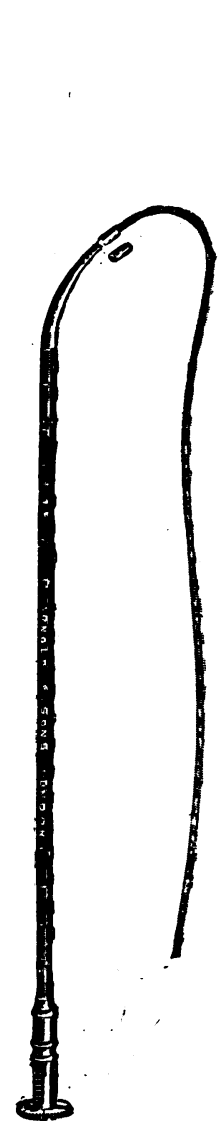

Fig. 2. Groove staff

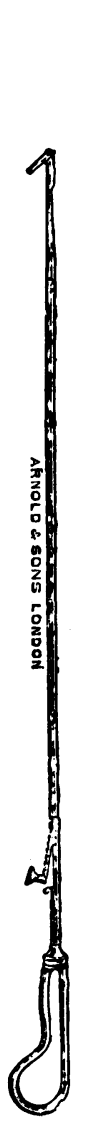

Fig. 2.

Knife which in staff.

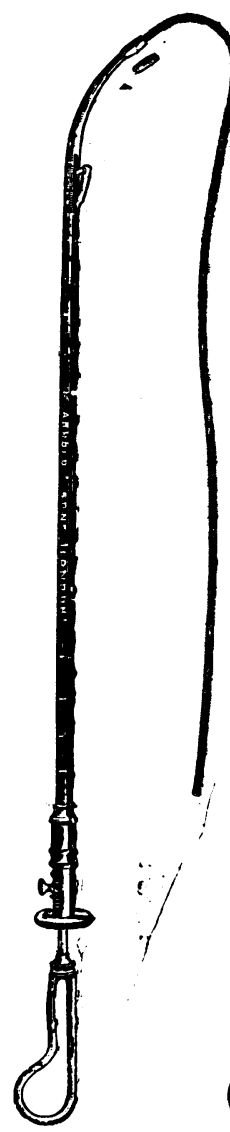

Fig. 3.

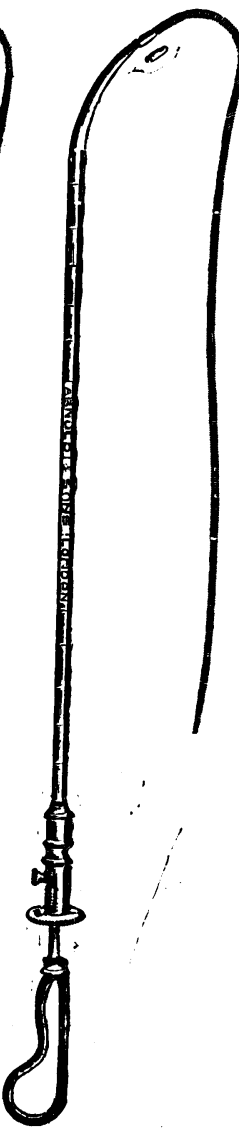

Fig. 4 . amples of cases which have proved to have been cured when examined years after the urethrotomy

Note.-The operation was done on December 7 th, rgor ; it was followed by no complication whatever, and on December 17 th No. $28 \mathrm{~mm}$. bougie was passed under cocaine. A very small quantity of blood followed the dilatation, but it soon diappeared. Since such rigid antiseptic precautions have been taken, a series of cases have pursued the same course.

\section{TOTAL EXTIRPATION OF THE PROSTATE : FREYER'S OPERATION. \\ By R. C. ELSWORTH, M.D.Edrn., F.R.C.S.Eng., Surgeon to the Swansea Hospital.}

I HAVE no desire to add anything to the inkshed which has already occurred on the subject of Freyer's operation for the total extirpation of the prostate, the possibility of accomplishing which seems, in the minds of some surgeons, to be doubtful. The following case may be of some interest, particularly as I found the operation easy of performance and the result highly satisfactory to the patient. There can be no doubt that the operation suggested and carried out by Mr. Freyer is a valuable addition to our means of dealing with a distressing malady and one which has hitherto been treated in an unsatisfactory manner. And I would like in this place to acknowledge my indebtedness to $\mathbf{M r}$. Freyer for bringing before the profession an easy and effective means of overcoming and removing what has been up to this time in many cases, the greatt st affliction of old age.

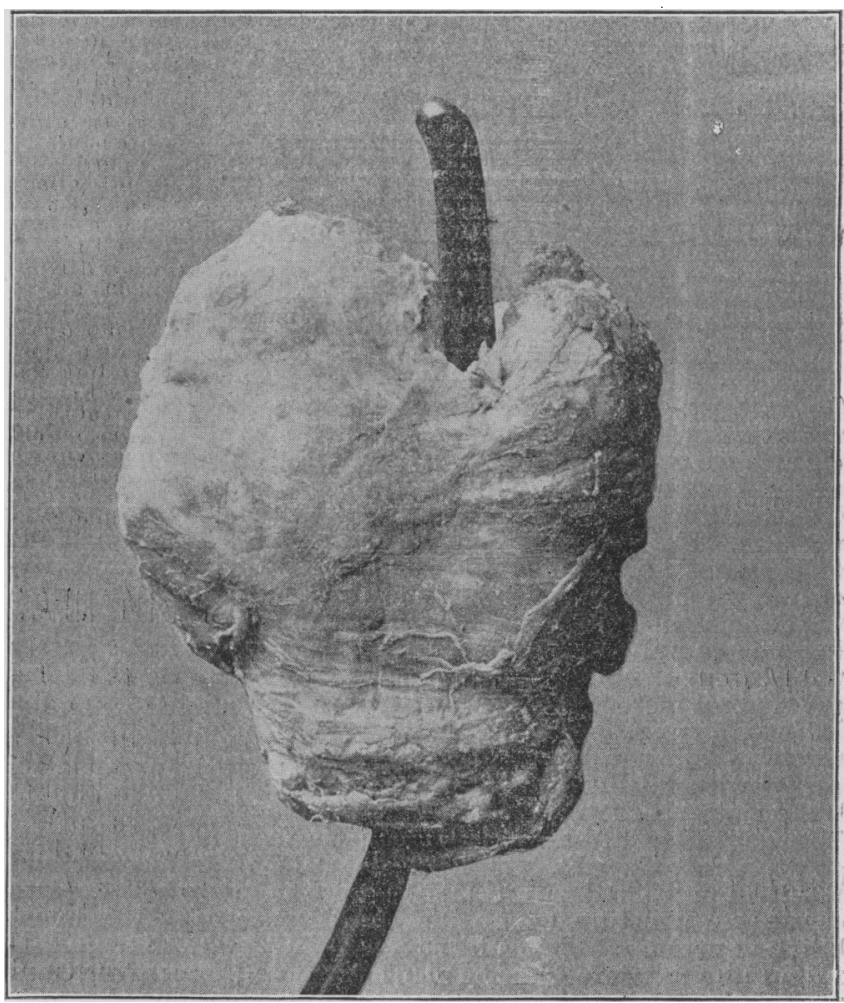

Fig. 1.

H. G., aged 67, was admitted into the Swansea Private Nursing Home on July and, I902, suffering from retention due to enlargement of the prostate. He had been compelled to use a catheter regularly for the last twelve months; but during the week preceding admission he had been unable to pass the catheter himself, and was obliged to seek the assistance of his medical man, who was able to relieve him for a couple of days, after which it was found impossible to vass a metal instrument, and for the next three days the bla lder was punctured suprapubically, drawing off a quantity ut blood-stained urine.

$\checkmark$ hen I first saw the patient the bladder was considerahly dis tended, and by means of a coudée catheter, which passed easily, the bladder was emptied. A'ter this the catheter was 